\title{
Syringomyelia associated with Cervical Spondylosis: A case report
}

\author{
Yavuz Samanci ${ }^{1}$, Suat Erol Celik ${ }^{2}$ \\ ${ }^{1}$ Neurosurgery Department, Ministry of Health Istanbul Training and Research Hospital, \\ Istanbul, Turkey \\ ${ }^{2}$ Neurosurgery Department, Ministry of Health Okmeydani Training and Research Hospital, \\ Istanbul, Turkey
}

\begin{abstract}
Although cervical spondylosis is an extremely common condition causing spinal cord compression, it is rarely involved in syringomyelia formation.

Here we describe a case of syringomyelia associated with cervical spondylosis.

Key words: Cervical spondylosis, Surgery, Syringomyelia.

\section{Case History}

A 57-year-old woman presented to our outpatient clinic complaining of left arm pain and weakness, progressing over 2 months. On neurological examination, there was muscle atrophy and dissociated sensory loss in the right arm and hand, and exaggerated reflexes in the upper limbs. The patient was subsequently referred for magnetic resonance imaging (MRI). Sagittal and axial T1 and T2 weighted sequences through the cervical and thoracic spine were performed. This demonstrated degenerative changes at C5-6 with a left foraminal disc protrusion compressing thecal sac. (Figures 1 and 2) An
\end{abstract}

unexpected cord syrinx was noted extending from C5 inferiorly to T1. (Figures 1 and 3) The craniocervical junction was normal, with no evidence of Chiari malformation. No cord mass lesion was demonstrated, and no other potential cause of syrinx was identified. Detailed questioning revealed no evidence to suggest previous spinal trauma or infection. No symptoms consistent with spinal ischemia or infarct were elicited.

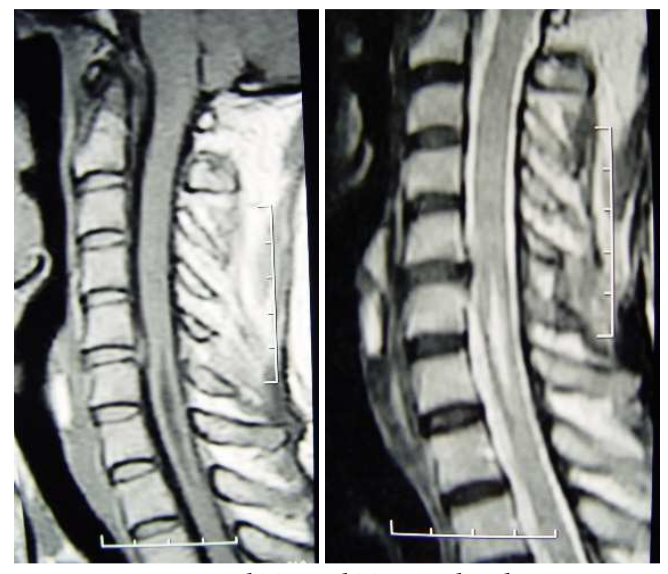

Figure 1 - Sagittal T1 and T2 weighted images through the cervical spine demonstrating spondylotic changes at C5/6 and caudal syrinx formation 
Anterior decompression with stabilization at C5-6 was carried out using a standard peek cage $(6 \mathrm{~mm}-12 \mathrm{~mm})$. Her left radicular arm pain disappeared immediately after surgery. MRI at 1 month after the surgery demonstrated remarkable reduction of the syrinx (Figure 4).

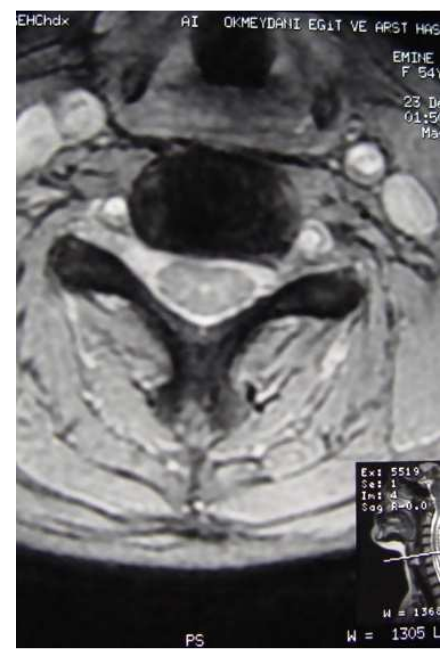

Figure 2 - Axial T2 weighted image at C5-6 level demonstrating a left foraminal disc protrusion

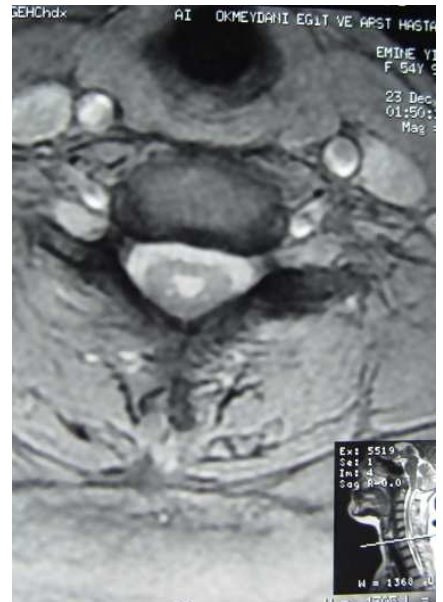

Figure 3 - Axial T2 weighted image at the level of C67 demonstrating the large central cord syrinx

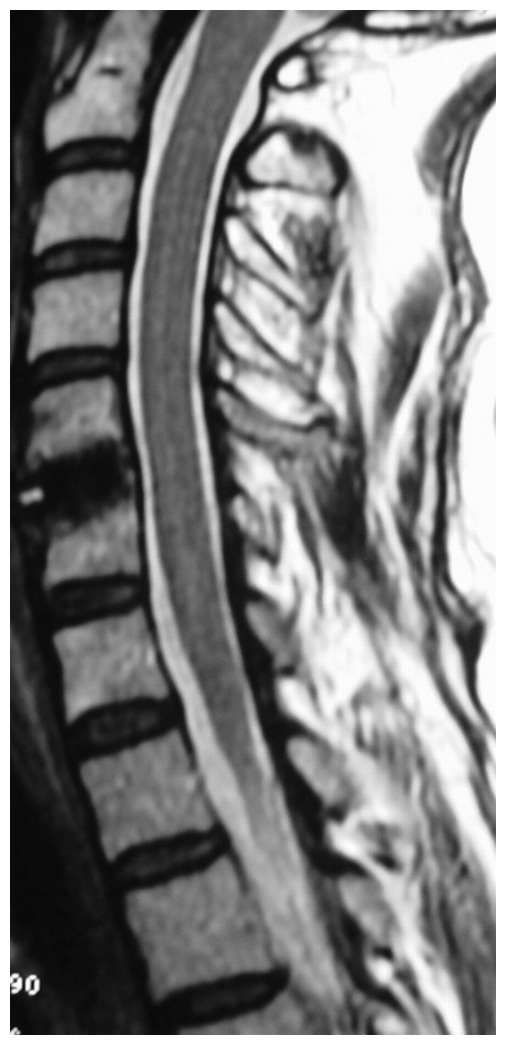

Figure 4 - Sagittal T2 weighted post-operative images through the cervical spine demonstrating remarkable reduction of the syrinx

\section{Discussion}

Syringomyelia, cystic cavitation of the spinal cord, is generally associated with congenital malformations as well as trauma and tumors. [1] Spinal spondylosis is an extremely common condition that has only rarely been described as a cause of syringomyelia. [2-5] T. Milhorat et al. reported 115 cases with non-neoplastic spinal cord syrinxes and there was only one patient whose syringomyelia was initially caused by cervical spondylosis. [2] 
DOI: 10.2478/romneu-2014-0027

Major theories of formation of the cyst are as follows: (1) Hydrodynamic theory of Gardner [6]: systolic pulsations are transmitted with each heartbeat from the intracranial cavity to the central canal. (2) Williams' theory [7]: maneuvers that raise cerebrospinal fluid (CSF) pressure cause "hydrodissection" through the spinal cord tissue. (3) Heiss-Oldfield theory [8]: occlusion at the foramen magnum causes CSF pulsations during cardiac systole to be transmitted through Virchow-Robin spaces which increases the extracellular fluid which coalesce to form a syrinx. It was lately proposed that subarachnoid obstruction leads to formation of transient increases in CSF pressure above the block, compared with below. Transmural hydrostatic effects may result in the collapse of vessels within the subarachnoid space above the block, and their dilatation below it. This may result in a combination of mechanical stress on the cord parenchyma and disruption of the blood-brain barrier, which in concert with raised intravascular pressure results in ultrafiltration of crystalloids and accumulation of fluid. [9] The fluid may dissect along planes of weakness within the cord resulting in the pathological appearance of a syrinx.

The etiology of syringomyelia in association with cervical spondylosis is not completely understood. Unanswered question is "why do patients with varying degrees of degenerative cervical spinal stenosis generally not get syringomyelia?" It may simply be that the degree and/or duration of CSF obstruction are not usually great enough in cases of spondylosis to engender a syrinx.
In our case, we excluded craniovertebral joint malformation and tumors by neuroradiological examination. The patient had no past history of trauma, tumor, spinal infarction, or meningitis. The absence of any other predisposing causes and our case demonstrating collapse of the syrinx and improvement of related symptoms after surgery suggest that there is a causative link between spondylosis and syringomyelia, rather than a simple coincidence.

\section{Conclusion}

The concurrence of cervical spondylosis and syrinx should warrant a detailed medical history and examination of imaging findings to exclude another cause for syrinx formation. In cases of syrinx associated with cervical spondylosis, treatment should be directed toward relieving the compressive lesion, rather than primary drainage of the syrinx.

\section{Correspondence:}

Yavuz SAMANCI, M.D.

Neurosurgery Department, Ministry of Health

Istanbul Training and Research Hospital

Kasap Ilyas Mah. Org. Abdurrahman Nafiz

Gurman Cad. Fatih

Phone: +90 (212) 4596000 Fax: +90 (212) 632

0060

34098, Istanbul, TURKEY

E-mail:mysamanci@hotmail.com

suatmd@gmail.com

\section{References}

1. Batzdorf U. Primary spinal syringomyelia. J Neurosurg Spine 3: 429-435, 2005.

2. Milhorat TH, Johnson RW, Milhorat RH, et al. Clinicopathological correlations in syringomyelia using 
axial magnetic resonance imaging. Neurosurgery: 37:20613, 1995.

3. Kaar GF, N'Dow JM, Bashir SH. Cervical spondylotic myelopathy with syringomyelia. Br J Neurosurg: 10:4135, 1996.

4. Rebai R, Boudawara MZ, Ben Yahia M, et sl. Syringomyelobulbia associated with cervical spondylosis: pathophysiology and therapeutic implications. Neurochirurgie: 48:120-3, 2002.

5. Kimura R, Park Y-S, Nakase H, et al. Syringomyelia caused by cervical spondylosis. Acta Neurochir: 146:1758, 2004.
6. Gardner WJ. Hydrodynamic mechanism of syringomyelia: its relationship to myelocele. J Neurol Neurosurg Psychiatry: 28:247-59, 1965 Jun.

7. Williams B. Syringomyelia. Br Med J: 14;1(5693):434, 1970 Feb.

8. Heiss JD, Patronas N, DeVroom HL,et al. Elucidating the pathophysiology of syringomyelia. J Neurosurg: 91(4):553-62. 1999 Oct.

9. Levine DN. The pathogenesis of syringomyelia associated with lesions at the foramen magnum: a critical review of existing theories and proposal of a new hypothesis. J Neurol Sci: 220:3-21, 2004. 